\title{
Comparison of Fatal Recreational Drug Overdoses between Celebrities and Non-Celebrities
}

\author{
Zara Ahmad' ${ }^{1}$, Jiin Kim², Aleksandra Udovica ${ }^{3}$, Renna Lee $^{4}$ \\ ${ }^{124}$ Department of Neuroscience, University of Toronto, ${ }^{3}$ Department of Psychology, University of Toronto
}

ABSTRACT: Previous studies have examined drug overdoses among celebrities, but not in comparison to the general population. This study's goal was to analyze whether celebrities have higher fatal overdose rates from recreational drug use than the non-celebrity population. It is often presumed that celebrities engage in more drug use to cope with their stressful and taxing lifestyles. To test this claim, we gathered a list of American celebrities that fatally overdosed on drugs from 1999 to 2017 (inclusive), as well as the number of overdoses in the general American population during this time frame. Certain drugs of interest were kept and less commonly occurring drugs that resulted in overdose were excluded, leaving us with opioids, heroin, cocaine, benzodiazepines, psychostimulants, and antidepressants. Descriptive statistics of both populations including gender and specific professions of celebrities were collected. Then, an independent samples t-test was used to discover if there was a significant difference between fatal overdoses for the celebrity versus non-celebrity population in general and for each drug listed previously from the years 1999 to 2017. Pearson's correlation analysis was used to find if there was a difference in the yearly trend of overdoses for celebrities versus non-celebrities during the same time range. Descriptive statistics demonstrated that males comprised $62.9 \%$ of fatal overdoses for non-celebrities and $73.5 \%$ for celebrities, and musicians (24.3\%), athletes (23.6\%), and actors (17.6\%) tend to overdose the most in terms of celebrity professions. In addition, the results from the t-test showed that non-celebrities had not fatally overdosed at significantly different rates than celebrities from 1999 to 2017 , as well as overdosed at no significantly different rate for each individual drug than celebrities during this time frame. However, the exceptions were any opioids and benzodiazepines, for which the former group overdosed at a significantly higher rate. Pearson's correlation analysis yielded an insignificant negative correlation between fatal overdoses and years passed between 1999 to 2017 for celebrities, and a significant positive correlation between fatal overdoses and years passed for non-celebrities. The judgmental heuristics may make us believe that more celebrities fatally overdose than non-celebrities, and that this presumption could potentially be problematic because celebrities have a massive influence on society, which could lead the general population to engage in these self- destructive behaviours themselves.

KEYWORDS: Recreational drugs, celebrities, non-celebrities, fatal overdose, social contagion

\section{INTRODUCTION}

Drug overdoses result from a "super- dosage," [1] which occurs when one or more substances induce physiological changes in the body from continuous drug abuse over a short amount of time. The consequences resulting from the "super-dosage" often involve the need of immediate medical attention to prevent death [1]. Studies have shown that celebrities are more likely to have a shortened life expectancy compared to the general population, with one of the biggest contributors being drug overdose [2], [3]. The wide accessibility of drugs, and a stressful environment including irregular schedules, travel and lack of privacy, can be risk factors for drug abuse [4], [5]. Notably, the privacy of celebrities is often invaded due to media attention, which has likely increased over the years due to heightened social media use. These are factors that surround celebrities conceivably more than non- celebrities, so perhaps the former group is more prone to drug abuse.

Through the same media channels, celebrities have a huge influence on the general public [6], [7], [8]. Studies show how actions of celebrities, such as suicide, have a negative social contagion effect on society [9], [10], [11]. As such, it is important to understand drug abuse among celebrities, in order to prevent further drug abuse among them, and consequently 
in the general public. Previous studies [3], [4] have examined the differences in the type of drug use in the celebrity population. However, they have not examined the differences in drug overdose deaths between celebrities and non-celebrities. In this study, the drugs involved in fatal drug overdose between American celebrities and the general American population were compared to further investigate how differences in drug types affect the prevalence of fatal overdose between celebrities and non- celebrities. The hypothesis was made that during the years 1999 to 2017, the fatal overdose rates of celebrities was significantly greater than for non-celebrities. Furthermore, since media use has increased over this period, and the media enables potentially stressful privacy invasion, another hypothesis was made that the numbers of celebrity deaths from drug overdose increased over this time frame. It follows then that the number of deaths among non-celebrities from drugs would increase as well, due to the social contagion effect.

\section{METHODS}

\section{Participant}

A list from Wikipedia called "List of deaths by year" was located [12]. A person was considered a celebrity by virtue of being on the list and thus, having their own Wikipedia page. Total American celebrity deaths from 1999 to 2017 were extracted from this list. Another dataset from Wikipedia called "List of deaths from drug overdose and intoxication" was found [13]. This list was filtered so that only the celebrities who met the inclusion criteria were included. The inclusion criteria consisted of being an American and dying from one or more of: opioids, heroin, cocaine, psychostimulants, benzodiazepines, or antidepressants, at some time between 1999 to 2017 (inclusive). Additionally, unspecified deaths were included in the total overdose death count.

\section{Descriptive Data}

A pie chart of the professions of the celebrities who died was created (Figure 1). Information about gender proportions was also calculated.

\section{Drug Comparisons with the General Population}

The drugs of interest were inspired by a table found from the National Institute of Drug Abuse [14], which detailed the number of people who died from a drug overdose in the Uni- ted States from 1999 to 2017. The original table was simplified so that seven categories were left: total overdose deaths, any opioid, heroin, cocaine, psychostimulants, benzodiazepines, and antidepressants.

The drugs involved in celebrity deaths were categorized into these groups. This celebrity data was then manually inputted into a similar version of the simplified table (explained in the above paragraph).

Rates per 100,000 by year were then calculated by dividing the deaths from overdoses by total celebrity deaths, for total overdoses and for each drug group separately.

Next, data from 1999 to 2017 for the number of total deaths in America [15], were located. For each year between 1999 to 2017, the total American deaths were subtracted by the total celebrity deaths from that year, yielding total non-celebrity deaths. The same was done with the overdose datasets to yield non-celebrity overdose deaths. Using the resulting data, the rate per 100,000 deaths for the non-celebrity U.S. population was calculated by year and drug group, and for total overdoses.

Once two comparable data sets were formed, the independent samples t-test on IBM SPSS $₫$ version 26 was performed to compare the same category between celebrity deaths and overall deaths. Thus, a total of seven t-tests were conducted - one for each drug category, and one for the total overdose rate.

Additionally, the same software was used to calculate the Pearson correlations for the number of deaths vs. year for both celebrities and non-celebrities.

\section{RESULTS}

\section{Descriptive Data on Celebrity Deaths}

After filtering the data, 117 people met the inclusion criteria. Many of the celebrities who died due to drug overdose were actors, athletes and musicians (Figure 1).

The majority of those who died from drug overdose from 1999 to 2017 were male for both celebrities and non-celebrities.

\section{Comparison of Drugs of Use for Fatal Overdose between Celebrities and Non-Celebrities}

Total Overdoses: In a two-tailed independent samples t-test with an alpha level of 0.05 , we found that non- celebrities did not have a significantly different total overdose rate 


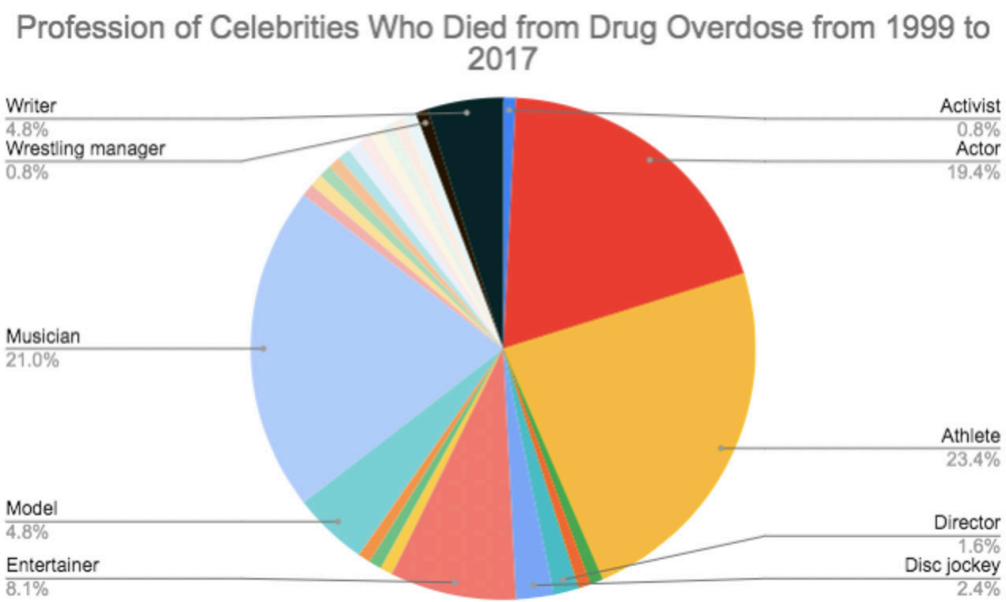

Figure 1. The profession of celebrities who died of drug overdose from 1999-2017.

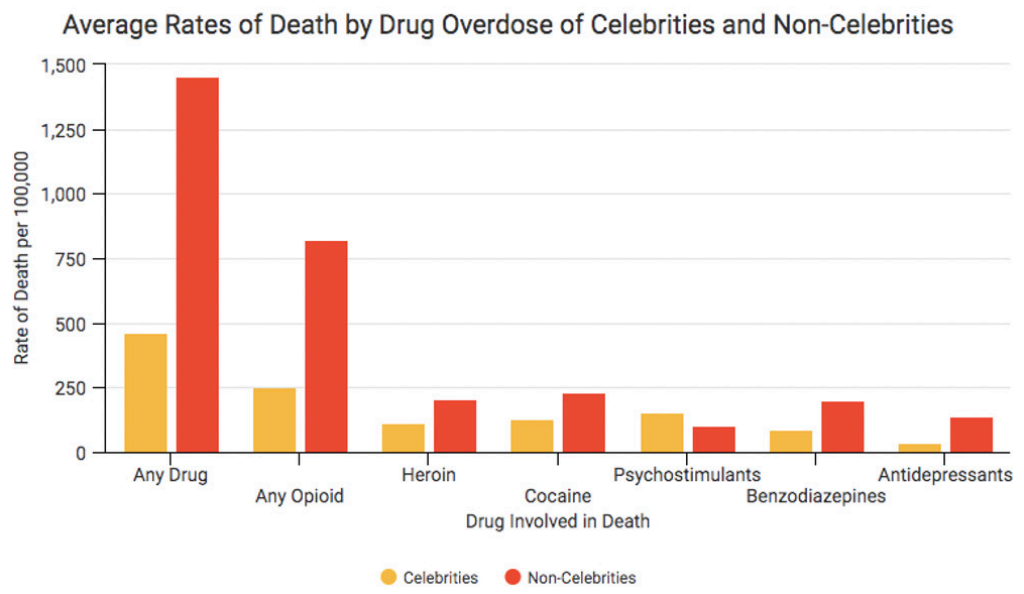

Figure 2. Average rates of death by drug overdose of celebrities and non-celebrities.

from the years 1999 to $2017(M=1451.63, S D=495.05)$ when compared to the celebrities $(M=463.53, S D=258.31), t(27.125)$ $=-7.713, \mathrm{p}=0.057$.

Overdoses for Individual Drugs: Non-celebrities were not found to have a significantly different overdose rate from heroin, cocaine, psychostimulants and antidepressants from the years 1999 to $2017(M=202.74, S D=171.71 ; M=229.37$, $S D=86.61 ; M=102.05, S D=92.86 ; M=138, S D=38.20)$, than the celebrities (refer to Table 1). However, non-celebrities were found to have a significantly higher rate of overdose from any opioid and benzodiazepines from the years 1999 to 2017 $(M=820.00, S D=373.62 ; M=202.16, S D=112.61$ ) than celebrities $(M=252.53, S D=164.37 ; M=85.42, S D=53.28), t(24.716)=-6.06$, $p=0.02, d=1.97 ; t(25.674)=-4.084, p=0.001, d=1.32$. (Table 1).

For illustrative purposes, a graph contrasting the average rates of death between the two groups is included (Figure 2).

\section{Correlation between Number of Deaths and Year}

The correlation between the number of drug overdose deaths and year (from 1999 to 2017) was calculated. The results for this correlation for non-celebrities and celebrities are presented in Tables 2 and 3 respectively, and as a graph in Figure 3.

For illustrative purposes, a graph is included in this report (Figure 5).

There was a significant positive correlation between years elapsed from 1999 to 2017 and drug overdoses for non- celebrities, $r=0.969, p<0.001$. There was a slight negative correlation between years elapsed and fatal drug overdoses for celebrities. However, it was not significant, $r=-0.406, p=0.084$.

\section{DISCUSSION}

The main findings of the current study were obtained from 
Table 1. Difference in rates (per 100,000 persons) of types of drug used to fatally overdose between celebrities and non-celebrities from 1999 to 2017.

\begin{tabular}{|c|c|c|c|c|c|c|}
\hline \multicolumn{7}{|c|}{$\begin{array}{l}\text { Difference in Rates (per } 100000 \text { Persons) of Types of Drug Used to Fatally } \\
\text { Overdose between Celebrities and Non-Celebrities from } 1999 \text { to } 2017\end{array}$} \\
\hline & \multicolumn{2}{|c|}{ Celebrities } & \multicolumn{2}{|c|}{ Non-Celebrities } & \multirow[b]{2}{*}{$t$-test } & \multirow[b]{2}{*}{ Cohen's d } \\
\hline & $\mathrm{M}$ & SD & $\mathrm{M}$ & SD & & \\
\hline Total Overdose & 463.5263 & 258.31341 & 1451.6316 & 495.04996 & ns & \\
\hline Any Opioid & 252.5263 & 164.37199 & 820 & 373.62057 & $-6.06^{* *}$ & 1.966118 \\
\hline Heroin & 113.8421 & 129.69934 & 202.7368 & 171.71095 & ns & \\
\hline Cocaine & 127.7368 & 97.49692 & 229.3684 & 86.61422 & ns & \\
\hline Psychostimulants & 153.8947 & 120.0018 & 102.0526 & 92.85621 & ns & \\
\hline Benzodiazepines & 85.4211 & 53.2826 & 202.1579 & 112.61452 & $-4.084^{*}$ & 1.325141 \\
\hline Antidepressants & 36.0526 & 63.14135 & 138 & 38.20122 & ns & \\
\hline
\end{tabular}

Table 2. Non-celebrity death rate per 100,000 vs year.

\begin{tabular}{|c|c|c|c|}
\hline \multicolumn{4}{|c|}{ Non-Celebrity Death Rate Per 100000 vs Year } \\
\hline & & Year & Death Rate \\
\hline \multirow[t]{3}{*}{ Year } & Pearson Correlation & 1 & $.969^{* *}$ \\
\hline & Sig. (2-tailed) & & 0 \\
\hline & $\mathrm{N}$ & 19 & 19 \\
\hline \multirow[t]{3}{*}{ Death Rate } & Pearson Correlation & $.969^{* *}$ & 1 \\
\hline & Sig. (2-tailed) & 0 & \\
\hline & $\mathrm{N}$ & 19 & 19 \\
\hline \multicolumn{4}{|c|}{${ }^{\star \star}$ Correlation is significant at the 0.01 level (2-tailed). } \\
\hline
\end{tabular}

Table 3. Celebrity death rate per 100,000 vs year.

\begin{tabular}{|l|l|r|r|}
\hline \multicolumn{3}{|l|}{ Celebrity Death Rate Per $\mathbf{1 0 0} 000$ vs Year } & \\
\hline \multirow{3}{*}{ Year } & Year & Death Rate \\
\hline \multirow{2}{*}{ Death Rate } & Pearson Correlation & 1 & -0.406 \\
& Sig. (2-tailed) & & 0.084 \\
& Pearson Correlation & -0.406 & 19 \\
& Sig. (2-tailed) & 0.084 & 1 \\
\hline & N & 19 & 19 \\
\hline
\end{tabular}




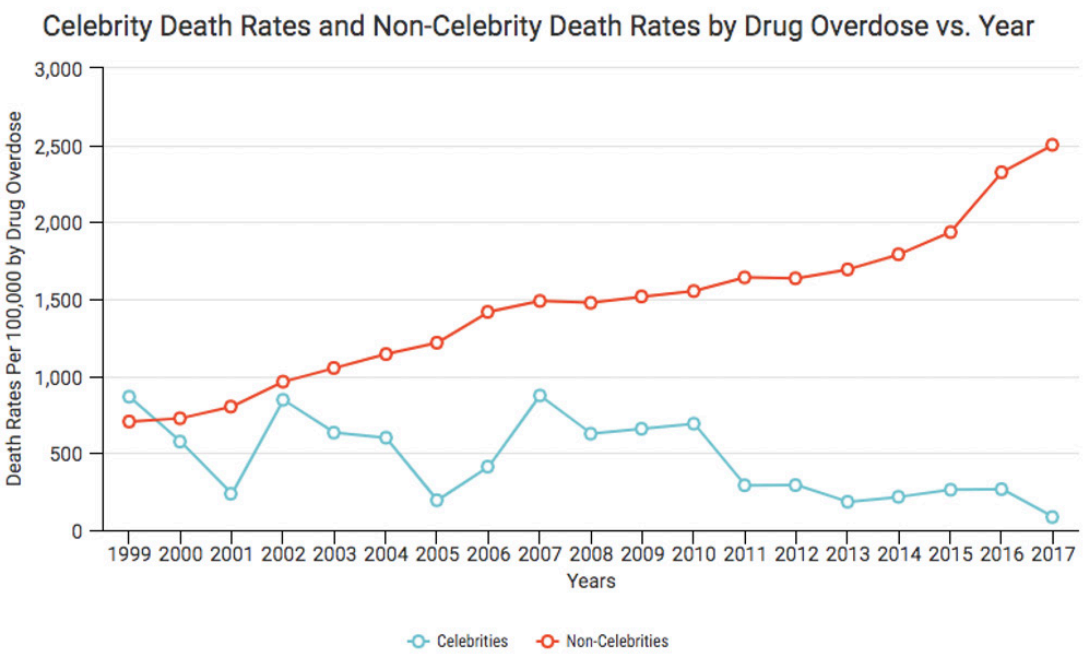

Figure 3. Celebrity death rates and non-celebrity death rates by drug overdose vs. year.

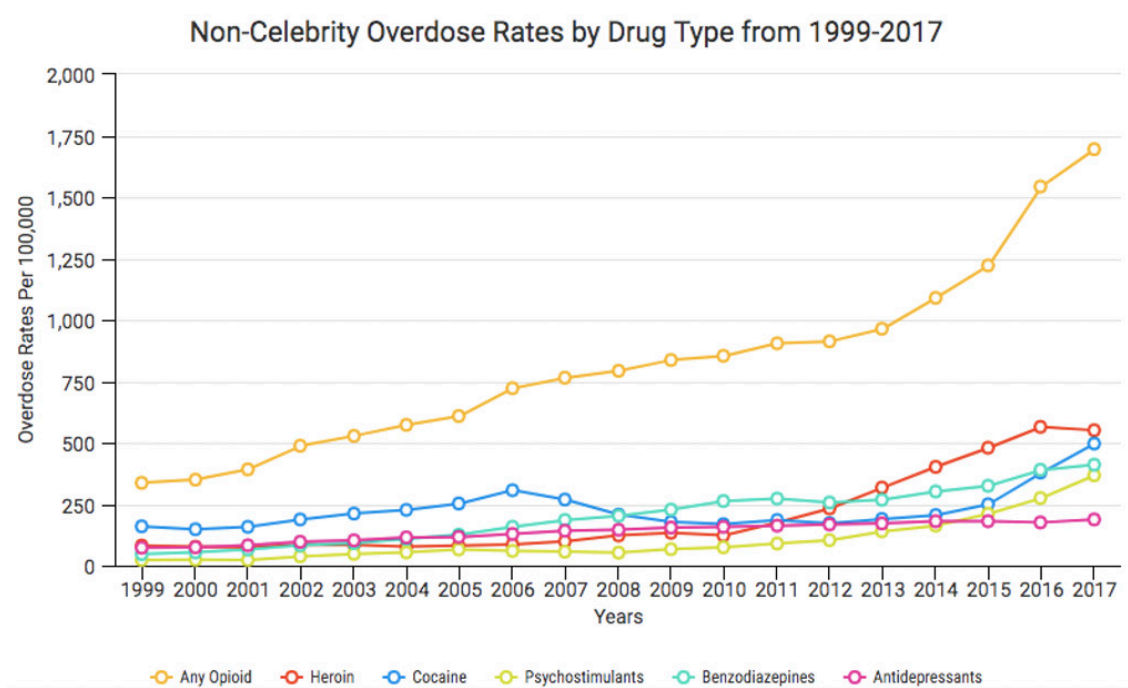

Figure 4. Non-celebrity overdose rates by drug type from 1999-2017

using an independent samples t-test. The result indicated that non-celebrities fatally overdosed at a rate not significantly different than celebrities from 1999 to 2017 both in general and for most drugs including heroin, cocaine, psychostimulants, and antidepressants. The only exceptions were any opioid and benzodiazepines, in which case noncelebrities fatally overdosed at a significantly higher rate. In addition, the Pearson correlation analysis demonstrated a significant positive correlation between years elapsed and lethal overdose for non-celebrities, while a non- significant negative correlation was found for celebrity lethal overdose and years elapsed.

These results reject the hypotheses, which were that 1) celebrities fatally overdose significantly more than non- celebrities both in general and for specific drugs (Figure 4 , Table 1), and 2) there is a significant positive correlation between celebrity death and year (Figure 5, Table 3). However, the third hypothesis, that there is a significant positive correlation between non-celebrity death and year, was supported (Figure 5, Table 2). This rejection of the first two hypotheses was unexpected, likely due to the strong effects of the availability heuristic, which is defined as "a judgmental heuristic in which a person evaluates the frequency of classes or the probability of events by availability, i.e., by the ease with which relevant instances come to mind" [17]. Celebrity news, including celebrity deaths, are constantly emphasized on our phones, TVs, and magazines, which makes them especially salient and therefore, makes us likely to believe 


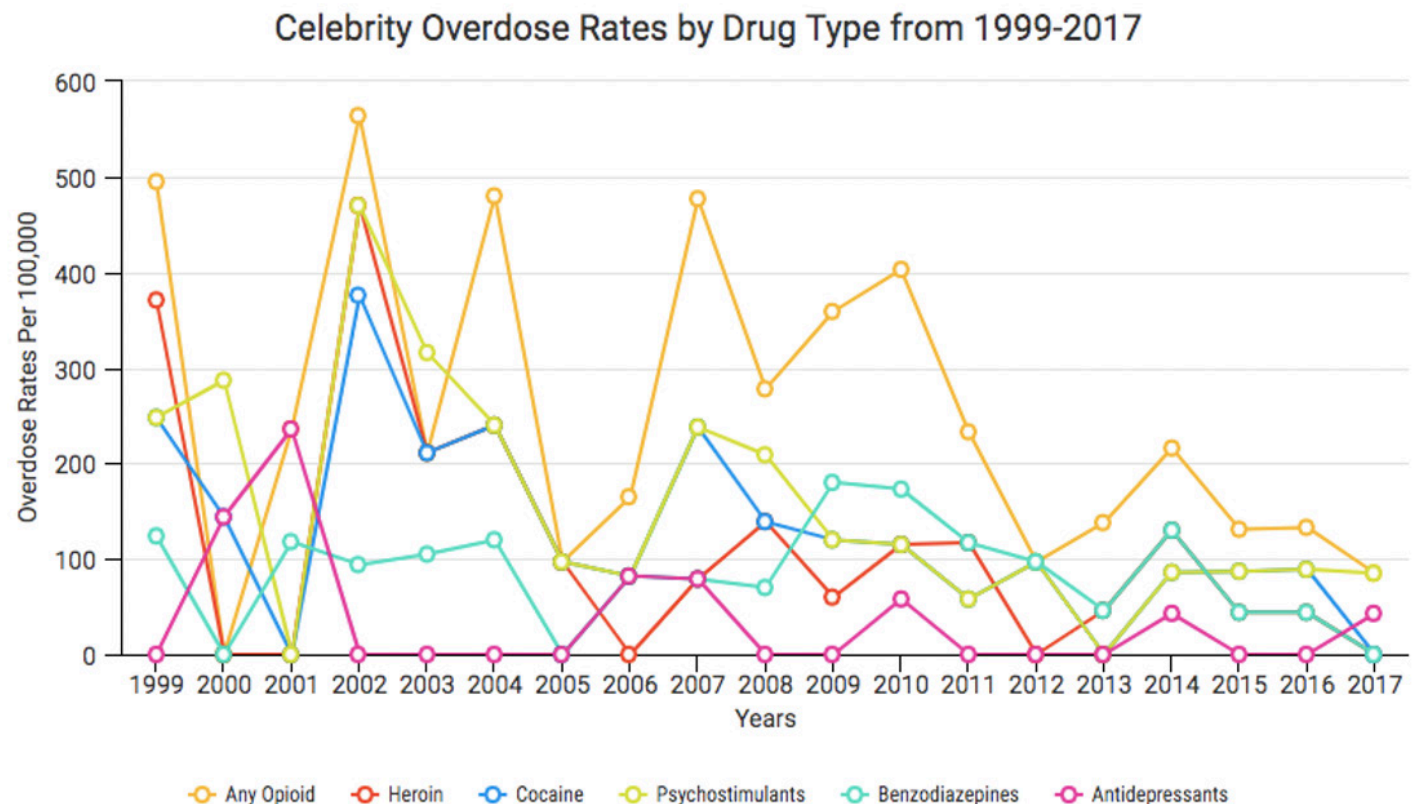

Figure 5. Celebrity overdose rates by drug type from 1999-2017

that celebrity drug overdoses are more prevalent than noncelebrity overdoses, which is a misconception.

Therefore, the implication of our findings is that media coverage might be inflating the number of fatal drug overdoses by celebrities when they are much rarer than overdoses in the general population. This phenomenon of believing that celebrities have a higher rate of drug overdoses may have a significant societal impact on the general population; one study demonstrated that media coverage of celebrity overdoses is too glamorized while not focusing enough on recovery [18]. This may be problematic for individuals who do not have the critical media skills to evaluate the situation surrounding the overdose of an idolized celebrity [11]. Furthermore, this may increase the incidence of fatal overdoses in the general population because of celebrities' substantial influence.

A limitation for this study is that the list of celebrities was compiled from Wikipedia [12], which is not a complete list and is susceptible to errors. Another limitation is that the analyses were based on U.S. data only, which cannot be generalized to other countries. Additionally, the study only analyzed six drug types and did not include common recreational drugs such as alcohol, marijuana, and nicotine. Also, the data of overdose deaths for both celebrities and non-celebrities spanned only from 1999 to 2017. Not only is this time range restrictive in range, but it does not account for the changes in the availability of drugs over time. Fentanyl, for instance, has become more available in recent years [19]. As noted from Figure 4, non-celebrities have been dying from opioid overdoses at an increasing rate over the past few years. In comparison, celebrity fatal drug overdoses show no such relationship (Figure 5). Thus, it is expected that non-celebrities will die at a higher rate than celebrities in recent years since the former group tends to fatally overdose more on opioids.

\section{CONCLUSIONS}

The present study shows differences in the number of drug overdoses and the involving drug types between celebrities and non-celebrities from 1999 to 2017. When the media discusses celebrity deaths due to overdose, perhaps it would be wise to also mention that these deaths are not common, so the general population does not normalize drug overdose deaths.

Future studies should consider a more accurate way to collect drug overdose statistics from the celebrity population. In addition, we could only find a full data set for lethal celebrity overdoses, so future studies could compile a data set of drugs that celebrities currently use so they can be compared to the general population. Finally, studies should also track the drug overdose trend after 2017 between non-celebrities and celebrities to see if it changes. 


\section{AKNOWLEDGEMENTS}

We would like to thank STEM Fellowship for allowing us to participate in the Undergraduate Big Data Challenge 2019 and for providing resources.

\section{REFERENCES}

1. Da Silva EA, Noto AR, Formigoni MLO. Death by drug overdose: impact on families. Journal of Psychoactive Drugs. 2007;39(3):301-306.

2. Kenny DT, Asher A. Life expectancy and cause of death in popular musicians. Med Probl Perform Art. 2016;31(1):37-44.

3. Just JM, Bleckwenn M, Schnaken- berg R, Skatulla P, Weckbecker K. Drug-related celebrity deaths: A crosssectional study. Substance abuse treatment, prevention, and policy. 2016;11(1):40.

4. Bellis MA, Hennell T, Lushey C, Hughes $K$, Tocque $K$, Ashton JR. Elvis to Eminem: quantifying the price of fame through early mortality of European and North American rock and pop stars. Journal of Epidemiology \& Community Health. 2007;61(10):896-901.

5. Tolson GHJ, Cuyjet MJ. Jazz and substance abuse: Road to creative genius or pathway to premature death. International Journal of Law and Psychiatry. 2007;30(6):530-538.

6. Wright SA. Blinding Lights: The Negative Effect of the Media on Celebrities. California Polytechnic State University, USA. 2008;

7. Hong SC, Lee J. People on the verge of death: evidence from impacts of celebrity suicides. Applied Economics. 2015;47(7):710-724.

8. Cheng AT, Hawton K, Chen TH, Yen AM, Chen CY, Chen LC, et al. The influence of media coverage of a celebrity suicide on subsequent sui- cide attempts. Journal of Clinical Psychiatry. 2007;68(6):862-866.

9. Ma-Kellams C, Baek JH, Or F. Suicide contagion in response to widely publicized celebrity deaths: The roles of depressed affect, death- thought accessibility, and attitudes. Psychology of popular media culture. 2018;7(2):164.

10. Kumar M, Dredze M, Coppersmith G, De Choudhury $M$. Detecting changes in suicide content man- ifested in social media following celebrity suicides. In: Proceedings of the 26th ACM conference on Hy- pertext \& Social Media. ACM; 2015. p. 85-94.

11. Shaw RL, Whitehead C, Giles DC. 'Crack down on the celebrity junkies': does media coverage of celebrity drug use pose a risk to young people? Health, risk \& so- ciety. 2010;12(6):575-589.

12. Wikipedia, List of deaths by year;. Accessed January 2020. Available from: https://en.wikipedia.org/wiki/ Lists_of_deaths_by_year
13. Wikipedia, List of deaths from drug overdose and intoxication;. Accessed June 2019. Available from: https://en.wikipedia.org/wiki/List_of_deaths_from_drug overdose_and_intoxication?fbclid=IwAR3IJ9Y-VBEPX7L-Li 4aKM1v2Is010qDcSAVXrqI6JS2yvVZ0JiZK5MV1I8

14. On Drug Abuse NI. Overdose Death Rates;. Accessed June 2019. Available from: https://www.drugabuse.gov/ related-topics/ trends statistics/overdose-death-rates.

15. Statista. Total number of fatalities in the United States 1990-2016 | Statistic;. Accessed June 2019. Available from: https://www.statista.com/ statistics/195920/number-of-deaths-in-the-unitedstates-since-1990/?fbclid=IwAR232wCU2HSN 4wZBfsu9j56Qk0h49VFMFd8t-ylBbQUEMUxs6̄-CbSkHB4jE.

16. Murphy SL, Xu J, Kochanek KD, Arias E. Mortality in the United States, 2017. Centers for Disease Control and Prevention; . Accessed June 2019. Available from: https:// www.cdc.gov/nchs/ products/databriefs/db328.htm.

17. Tversky A, Kahneman D. Availability: A heuristic for judging frequency and probability. Cognitive psychology. 1973;5(2):207-232.

18. Austin BJ. CELEBRITIES, DRINKS, AND DRUGS: A CRITICAL DISCOURSE ANALYSIS OF CELEBRITY SUBSTANCE ABUSE AS PORTRAYED IN THE NEW YORK TIMES. 2014;.

19. Jaimet K. The fentanyl crisis. Canadian Nurse;. Accessed August 2019. Available from: https://www. canadian-nurse.com/en/articles/issues/2017/januaryfebruary-2017/the-fentanyl-crisis 